\title{
Effect of B-field Dependent Particle Drifts on ELM Behavior in the DIII-D Boundary Plasma
}

M.E. Fenstermacher, A.W. Leonard, G.D. Porter, J.A. Boedo, N.H. Brooks, M. Groth, D.S. Gray, E.M. Hollmann, C.J. Lasnier, T.W. Petrie, M.R. Wade, J.G. Watkins, L. Zeng

This article was submitted to the $16^{\text {th }}$ International Conference on Plasma Surface Interactions

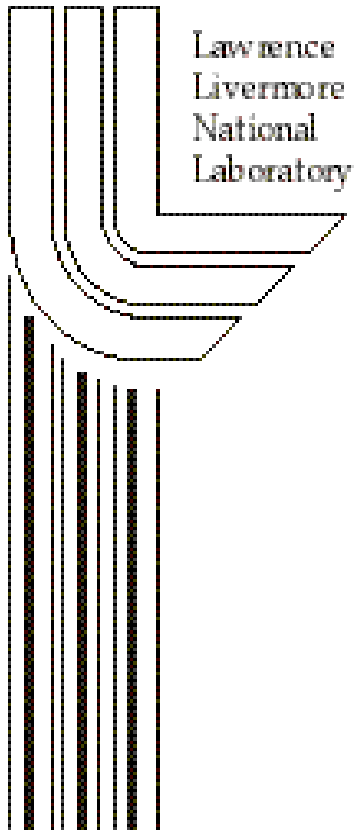

May 2004 


\section{DISCLAIMER}

This document was prepared as an account of work sponsored by an agency of the United States Government. Neither the United States Government nor the University of California nor any of their employees, makes any warranty, express or implied, or assumes any legal liability or responsibility for the accuracy, completeness, or usefulness of any information, apparatus, product, or process disclosed, or represents that its use would not infringe privately owned rights. Reference herein to any specific commercial product, process, or service by trade name, trademark, manufacturer, or otherwise, does not necessarily constitute or imply its endorsement, recommendation, or favoring by the United States Government or the University of California. The views and opinions of authors expressed herein do not necessarily state or reflect those of the United States Government or the University of California, and shall not be used for advertising or product endorsement purposes.

This is a preprint of a paper intended for publication in a journal or proceedings. Since changes may be made before publication, this preprint is made available with the understanding that it will not be cited or reproduced without the permission of the author.

This report has been reproduced directly from the best available copy.

Available to DOE and DOE contractors from the

Office of Scientific and Technical Information

P.O. Box 62, Oak Ridge, TN 37831

Prices available from (423) 576-8401

http: / / apollo.osti.gov/bridge/

Available to the public from the National Technical Information Service

U.S. Department of Commerce 5285 Port Royal Rd., Springfield, VA 22161 http:/ / www.ntis.gov/

OR

Lawrence Livermore National Laboratory Technical Information Department's Digital Library http:/ / www.llnl.gov/tid/Library.html 


\title{
Effect of B-field dependent particle drifts on ELM behavior in the DIII-D boundary plasma*
}

\author{
M.E. Fenstermacher, ${ }^{\mathrm{a}, *}$, A.W. Leonard ${ }^{\mathrm{b}}$, G.D. Porter ${ }^{\mathrm{a}}$, J.A. Boedo ${ }^{\mathrm{c}}$, N.H. Brooks ${ }^{\mathrm{b}}$, M. Groth ${ }^{\mathrm{a}}$, \\ D.S. Gray ${ }^{\mathrm{c}}$, E.M. Hollmann ${ }^{\mathrm{c}}$, C.J. Lasnier ${ }^{\mathrm{a}}$, T.W. Petrie ${ }^{\mathrm{b}}$, M.R. Wade ${ }^{\mathrm{d}}$, J.G. Watkins ${ }^{\mathrm{e}}$, L. Zeng ${ }^{\mathrm{f}}$ \\ ${ }^{a}$ Lawrence Livermore National Laborabory, Livermore, California 94550, USA \\ ${ }^{b}$ General Atomics, San Diego, California 92186-5608, USA \\ ${ }^{c}$ University of California at San Diego, La Jolla, California92093-0417, USA \\ ${ }^{d}$ Oak Ridge National Laborabory, Oak Ridge, Tennessee, USA \\ ${ }^{e}$ Sandia National Laboratories, Albuquerque, New Mexico 87185-1129, USA \\ ${ }^{f}$ University of California, Los Angeles, California 90095-1597 USA
}

\begin{abstract}
ELM effects in the DIII-D pedestal and boundary plasmas were measured with multiple fast diagnostics in matched, lower single null, ELMing H-mode discharges with the ion $\mathrm{Bx} \nabla \mathrm{B}$ drift toward and away from the divertor. Data show a strong dependence of the delay in inner vs outer divertor ELM $D_{\alpha}$ emission on drift direction, and a weaker drift dependence of the inner vs outer delay of the total radiated power, in addition to the strong density dependence seen in previous work [1]. Time dependent modeling of the boundary plasma during an ELM was done with the UEDGE code including a six-species fluid carbon model and the effect of B-field induced particle drifts [2]. The ELM perturbation was modeled as an instantaneous, outer midplane peaked, increase of diffusion coefficients from the top of the pedestal to the outer SOL. The simulations show delays in the ELM perturbation at the inner vs. outer divertor targets that are similar to the measured delays.
\end{abstract}

\footnotetext{
*Work supported by the U.S. Department of Energy under Contract Nos. W-7405-ENG-48, DE-AC0399ER54463, DE-AC05-00OR22725, DE-AC04-95ER85000, and Grant No. DE-FG03-01ER54615.
} 
JNM Keywords: Plasma properties - P0600, Theory and Modeling - T0100, Plasma Material Interactions - P0500, Experimental Techniques - E0500, Carbon - C0100

PSI-16 Keywords: ELM, DIII-D, SOL Plasma Boundary, Divertor Modeling, Divertor Plasma

PACS Codes: $52.40 . H F$, 52.55.Fa, 52.65.-y, 52.70.-m

Corresponding Author Address: LLNL, c/o General Atomics, PO Box 85608, MS13-466, San Diego CA 92186

Corresponding Author E-mail: fenstermacher1@llnl.gov

Presenting Author Address: LLNL, c/o General Atomics, PO Box 85608, MS13-466, San Diego CA 92186

Presenting Author E-mail: fenstermacher1@llnl.gov 


\section{Introduction}

The interaction of transient particle and energy pulses with the plasma facing components (PFCs) during edge localized modes (ELMs) is a critical issue for the viability of future high power tokamaks. Projections for ITER indicate that the divertor target lifetime could be limited to $\sim 10^{4}$ unmitigated Type-I ELMs ( several hundred full performance pulses) [3]. Finding operating regimes with good H-mode confinement and tolerable sized ELMs involves both the ELM instability physics in the pedestal and the behavior of the transient pulses from ELMs in the boundary plasma.

This paper focuses on the effect of B-field dependent particle drifts on ELM behavior in the inner vs the outer divertor of DIII-D as a function of plasma density. Previously the variation, with plasma density, in the delay of the inner vs the outer $D_{\alpha}$ emission transients during ELMs was found to be consistent with an ion convection model of SOL ELM propagation $[1,4]$. This paper examines the effect of changing SOL and divertor particle drifts on the convection of ELM perturbations in the boundary plasma.

\section{Description of Experiments}

For this study, lower single null (LSN), H-mode plasmas with Type-I ELMs and matched input parameters and plasma shape were produced with the ion $\mathrm{Bx} \nabla \mathrm{B}$ drift direction toward (normal) and away (reversed) from the divertor by changing the direction of the toroidal field. Matched operational parameters included major radius, $\mathrm{R}=1.7 \mathrm{~m}$, minor radius, $\mathrm{a}=$ $0.6 \mathrm{~m}$, elongation, $\kappa=1.8$, toroidal field, $\mathrm{Bt}=1.75 \mathrm{~T}$, and plasma current $\mathrm{Ip}=1.2$ or $1.4 \mathrm{MA}$. A moderate triangularity, $\delta=0.38$, moderate $\mathrm{X}$-point height, $\mathrm{Z}_{\mathrm{xpt}}=0.12 \mathrm{~m}$, shape was used to optimize the position of the divertor strikepoints and X-point region for diagnostics. Some matched plasmas were obtained at both $\mathrm{q}_{95}=3.2(1.4 \mathrm{MA})$ and $\mathrm{q}_{95}=3.7(1.2 \mathrm{MA})$. Previous work with the normal drifts direction [1] had $\mathrm{q}_{95}=3.2(1.4 \mathrm{MA})$ and used a higher triangularity, $\delta=0.52$. All available fast diagnostics were set to simultaneously cover an 
overlap window of $500 \mathrm{~ms}$ during the flattop ELMing phase of the discharge, although many of the diagnostics obtained fast data beyond this overlap window.

\section{Experimental Results}

Comparisons of coherently averaged ELM behavior from multiple diagnostics in matched low density $\left(\mathrm{n}_{\mathrm{e}}{ }^{\text {ped }} / \mathrm{n}_{\mathrm{Gr}} \sim 0.35\right)$ discharges with normal and reversed drifts show that the ELM onset throughout the boundary plasma is more sudden and the ELM effects more simultaneous in the two divertors for the reversed drifts case. The coherent averaging was done by aligning the data, in a time window about an ELM, to a time fiducial given by the peak of the $\mathrm{D}_{\alpha}$ emission from the midplane tangential filterscope looking through the top of the pedestal. Results from matched normal (Fig. 1) and reversed (Fig. 2) drifts cases show that the increase in MHD activity at ELM onset is more coincident in time with the pedestal thermal energy loss in the reversed drifts case. The enhanced MHD activity prior to pedestal energy loss, seen previously in the higher triangularity, normal drifts cases [1], is also seen frequently in these lower d discharges. However, there are many cases, especially in the reversed drift direction, with no time delay between enhanced MHD and evidence of pedestal energy loss. Finally, the inner and outer divertor peaks of the ELM transients in $D_{\alpha}$ and radiated power are also more nearly aligned in time in the reversed drifts case.

The delay of the $\mathrm{D}_{\alpha}$ emission transient during ELMs in the inner divertor compared with the outer divertor is much more pronounced in the normal drifts cases compared with the reversed drifts discharges. The delays of the ELM signal in the inner divertor compared with the outer divertor, normalized to the difference in ion transit time from the outer midplane to the two divertors, $\mathrm{t}_{\text {transit }}$, are shown in Fig. 3. Here, $\mathrm{t}_{\text {transit }}=\Delta \mathrm{L}_{\mathrm{c}} / \mathrm{C}_{\mathrm{s}}\left(\mathrm{T}_{\mathrm{e}}^{\text {ped }}\right)$ where $\Delta \mathrm{L}_{\mathrm{c}}=$ $\mathrm{L}_{\mathrm{c}}^{\text {in }}-\mathrm{L}_{\mathrm{c}}^{\text {out }}, \mathrm{L}_{\mathrm{c}}^{\text {in (out) }}$ are the connection lengths between the outer midplane and the ISP (OSP) along the SOL field line connecting the locations of the $\mathrm{D}_{\alpha}$ view spots on the targets,

and $\mathrm{C}_{\mathrm{s}}\left(\mathrm{T}_{\mathrm{e}}^{\mathrm{ped}}\right)$ is the ion sound speed evaluated at the pedestal electron temperature before the ELM onset. The delay was obtained by selecting $\mathrm{D}_{\alpha}$ data in a time window about each 
ELM, cross correlating the selected data from inner and outer divertor viewing chords, and fitting a Gaussian to the correlation function to find the most probable delay time. As seen previously in higher $\delta$ plasmas [1], there is a clear delay (Fig. 3a) of the inner $\mathrm{D}_{\alpha}$ compared with the outer $\mathrm{D}_{\alpha}$ in the normal drifts discharges with moderate to high density, $0.35<$ $\mathrm{n}_{\mathrm{e}}{ }^{\text {ped }} / \mathrm{n}_{\mathrm{Gr}}<0.8$, and this delay scales with $\mathrm{t}_{\text {transit. }}$ The normalized delay becomes very small at low density, $0.15<\mathrm{n}_{\mathrm{e}}{ }^{\mathrm{ped}} / \mathrm{n}_{\mathrm{Gr}}<0.30$. In the reversed drifts case (Fig. 3b), the normalized delay is a weakly increasing function of pedestal density, with much smaller delay at moderate to high density than in the normal drifts cases.

Very little delay is observed in the transient radiated power of the inner divertor compared with the outer divertor, independent of drifts direction; for many ELMs in the normal drifts case the ELM effect on the radiated power actually appears first in the inner divertor then in the outer divertor. Here the delay was obtained using the procedure described above applied to chords of the fast AXUV bolometer system [5]. In the normal drifts discharges, Fig. 4a, positive delays (outer Prad transients before inner Prad transients) are observed in the high $\delta$ discharges at high density and small delays are observed at low density. $\mathrm{P}_{\text {rad }}$ transients in the lower $\delta$ discharges frequently appear first in the inner divertor (negative delay) for both the low and higher $\mathrm{q}_{95}$ plasmas. In the reversed drifts plasmas small delay is observed for most of the ELMs (albeit with significant scatter) in the higher $\mathrm{q}_{95}$ plasmas; the outer $\mathrm{P}_{\text {rad }}$ chord was saturated in the low $\mathrm{q}_{95}$ plasmas.

\section{UEDGE Modeling}

The UEDGE multi-species fluid code [6] was used in time-dependent mode, with a large increase in transport coefficients for a short period, to simulate the ELM perturbation of the pedestal and SOL. The initial steady state H-mode solution prior to the ELM perturbation included a fluid neutrals model, all six charges species of carbon in a fluid impurities model and particle drift effects [7]. Neutrals in the model are assumed to be equilibrated by chargeexchange with the local ion temperature and carbon sources from physical and chemical 
sputtering are calculated from the Haasz model [8]. The drift effects include ion $\mathrm{Bx} \nabla \mathrm{B}$ and $\mathrm{ExB}$ drifts, but in these initial simulations the magnitude of the drifts was set to $40 \%$ of the full value predicted by theory. Work attempting to get converged solutions for stronger drifts, approaching the theoretical values, is in progress. Guided by the average ELM behavior of Fig. 1 and Ref. 1, the ELM perturbation was modeled by an instantaneous 10x increase in the particle diffusion coefficient for $550 \mu \mathrm{s}$. For the last $50 \mu \mathrm{s}$ of this period the energy transport coefficients were also increased by 10x over the steady state values. The perturbation was applied with a parabolic profile across the radius from the top of the pedestal to the outer SOL, and with a Gaussian poloidal profile peaked at the outer midplane with a e-folding poloidal length of $80 \mathrm{~cm}$.

ELM simulations for this study were based on steady-state UEDGE solutions for ELMing $\mathrm{H}$-mode plasmas with triangularity, X-point height, and $\mathrm{q}_{95}$ comparable to the high $\mathrm{d}$, Zxpt discharges in the ELM characterization study. The plasma shape in the simulations had $\delta=0.76, \mathrm{Z}_{\mathrm{xpt}}=0.24 \mathrm{~m}$ and $\mathrm{q} 95=4.0$. This shape was used because the higher triangularity and X-point height allowed UEDGE steady-state and ELM perturbation simulations to be obtained with the largest fraction of the theoretical drift effects included. Work to generate simulations with the theoretical drifts in the shape of the experimental discharges is in progress.

Simulations of chord-integrated $\mathrm{D}_{\alpha}$ and radiated power signals, generated from the UEDGE time dependent simulations, showed positively correlated delay of the inner divertor signals from the outer divertor signals in the forward drift cases and small delay of the inner vs outer radiated power in the reversed drift case, in agreement with experimental data at moderate to high density. The simulated chordal $D_{\alpha}$ (Fig. 5) and $P_{\text {rad }}$ (Fig. 6) signals were calculated by integrating through the UEDGE 2D solution from the experimental diagnostic observation point to each of the target plate segments of the UEDGE solution. Positive correlation (both signals increasing during the ELM transient) is predicted for the forward drift case (Figs. 5a and 6a) with larger in-out delays of the Da emission than of the total 
radiated power. This is consistent with the data at moderate density in Fig. 3. Positive correlation of Prad is also calculated in the reversed drifts case (Fig. 6b) with small in-out delay similar to the data in Fig. 4b. However, the UEDGE solution produces a mixture of positive and anti-correlation (one signal increasing and one decreasing during the ELM) in the $\mathrm{D}_{\alpha}$ signals between the inner and outer divertor in the reversed drift case. This is not observed in the data from the limited number of diagnostic view chords.

\section{Discussion and Summary}

The significant differences in the SOL and divertor behavior of ELM transients for LSN plasmas with forward and reversed drifts may be due to either differences in the pre-ELM condition of the SOL and divertor plasmas, or to the effect of the change in drifts direction during the ELM transient itself. For moderate pedestal density, the pre-ELM conditions in the forward drifts case include a cold, high density, detached inner divertor and a hot attached outer divertor. In contrast both divertors are attached in the reversed drifts case. The delays of both the $\mathrm{D}_{\alpha}$ and $\mathrm{P}_{\text {rad }}$ transients between the inner and outer divertors are more sensitive to operating density in the forward drifts case. This may be due in part to the unbalanced conditions of the divertor legs before the ELM perturbation arrives, in particular the sensitivity of the inner leg detachment to operating density. $\mathrm{D}_{\alpha}$ and $\mathrm{P}_{\text {rad }}$ transients occur nearly simultaneously in the two attached divertor legs for the reversed drifts case. Initial UEDGE modeling of ELMs with the effect of drifts included shows the significant inner vs outer delays in the forward drifts case but produces anti-correlated transients for the reversed drifts case that are not seen experimentally. Future modeling will focus on better benchmarking to the pre-ELM conditions including plasma shape, incorporating the full theoretical drifts and developing a more realistic model of the ELM perturbation. 


\section{Acknowledgement}

Work supported by U.S. Department of Energy under Contract DE-AC03-99ER54463, and Grants DE-FG03-97ER54415, DE-FG02-92ER54141, DE-FG03-96ER54373, and DEFG03-01ER54615.

\section{References}

[1] M.E. Fenstermacher et al., Plasma Phys Control. Fusion 45 (2003) 1597.

[2] T.D. Rognlien et al., J. Nucl. Mater. 313-316 (2003) 1000.

[3] G. Federici et al., J. Nucl. Mater. 313-316 (2003)11.

[4] M.E. Fenstermacher et al., Proc. ??st EPS Conf. on Plas. Phys. And Contr. Fus, St. Petersburg, Russia, July 2003.

[5] Gray, D.S. et al., Rev. Sci. Instrum., in press (2004).

[6] Rognlien, T.D. et al., J. Nucl. Mater. 196-198,(1992) 80.

[7] Rognlien, T.D. et al., J. Nucl. Mater., 313-316, (2003), 1000.

[8] Davis, J.W., Haasz, A.A., J. Nucl, Mater., 241-243 (1997) 37. 


\section{Figure Captions}

Fig. 1 Average ELM behavior in a forward drift discharge at moderate density, neped $/ \mathrm{nGr}=0.35$ for $(\mathrm{a}) \mathrm{dB} / \mathrm{dt}(\mathrm{G} / \mathrm{s})$, (b) pedestal soft X-ray signal, (c) top of the pedestal ECE signal, (d) pedestal (solid) and midplane SOL (dashed) Da, (e) inner (solid) and outer (dashed) divertor Da, (f) outer divertor leg ne, (g) outer strikepoint current integrated on a target tiel, (h) inner (solid) and outer (dashed) divertor radiated power.

Fig. 2 Average ELM behavior in a revbersed drift discharge at moderate density, neped $/ \mathrm{nGr}=0.35$. Curves are the same quantities defined in Fig. 1.

Fig. 3 Inner vs. outer delay of (a) Da emission and (b) total radiated power, normalized to transit time of ions at the pedestal energy, as a function of normalized pedestal density for the forward drift discharges.

Fig. 4 Parameters of Fig. 3 for the reversed drift discharges.

Fig. 5 Correlation functions of inner vs outer delay of (a) Da emission and (b) total radiated power, normalized to transit time of ions at the pedestal energy, for various flux surfaces in the forward drift UEDGE simulation. Flux surface radii shown are mapped to outer midplane.

Fig. 6 Parameters of Fig. 5 for the reversed drift UEDGE simulation. 


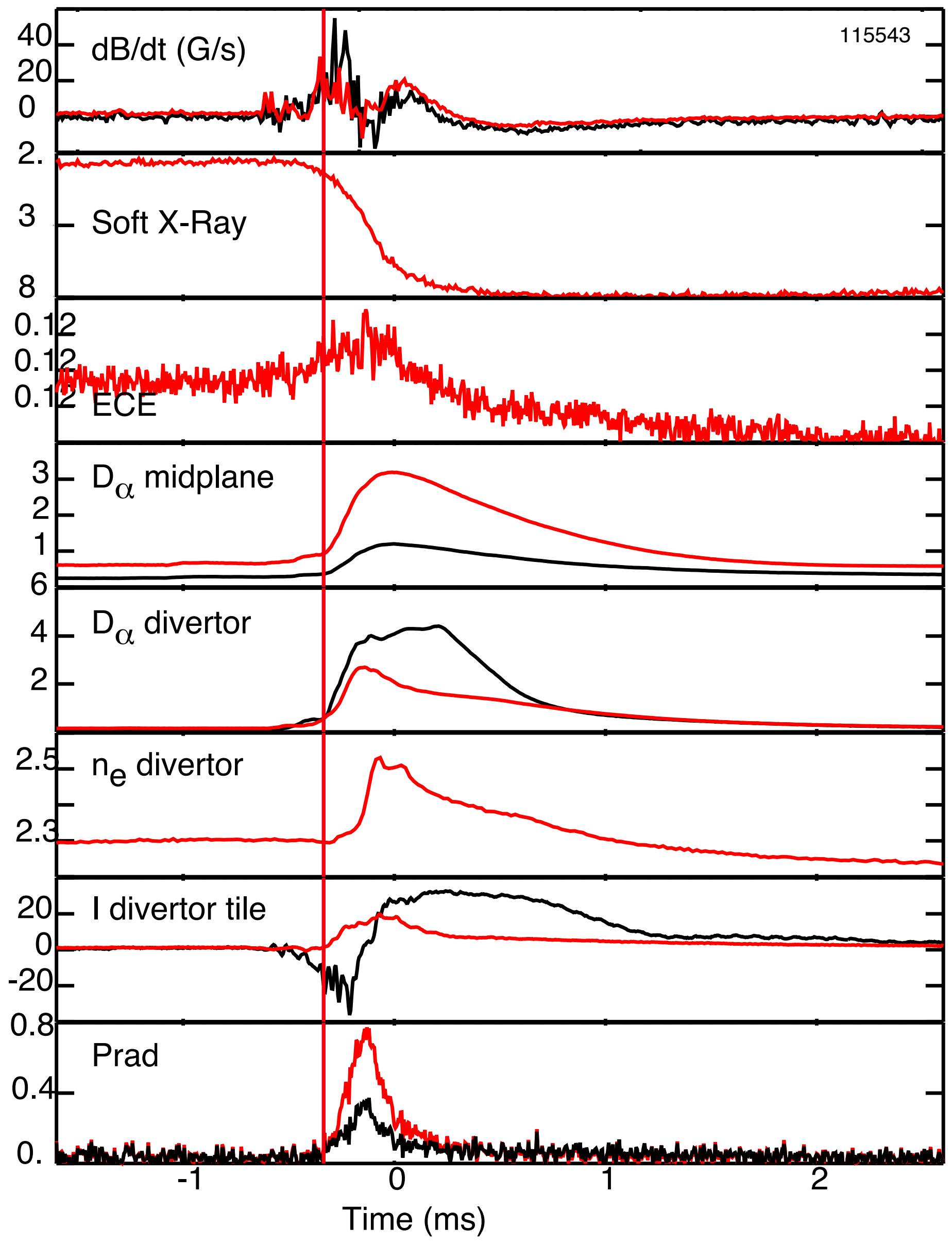

Fig. 1 


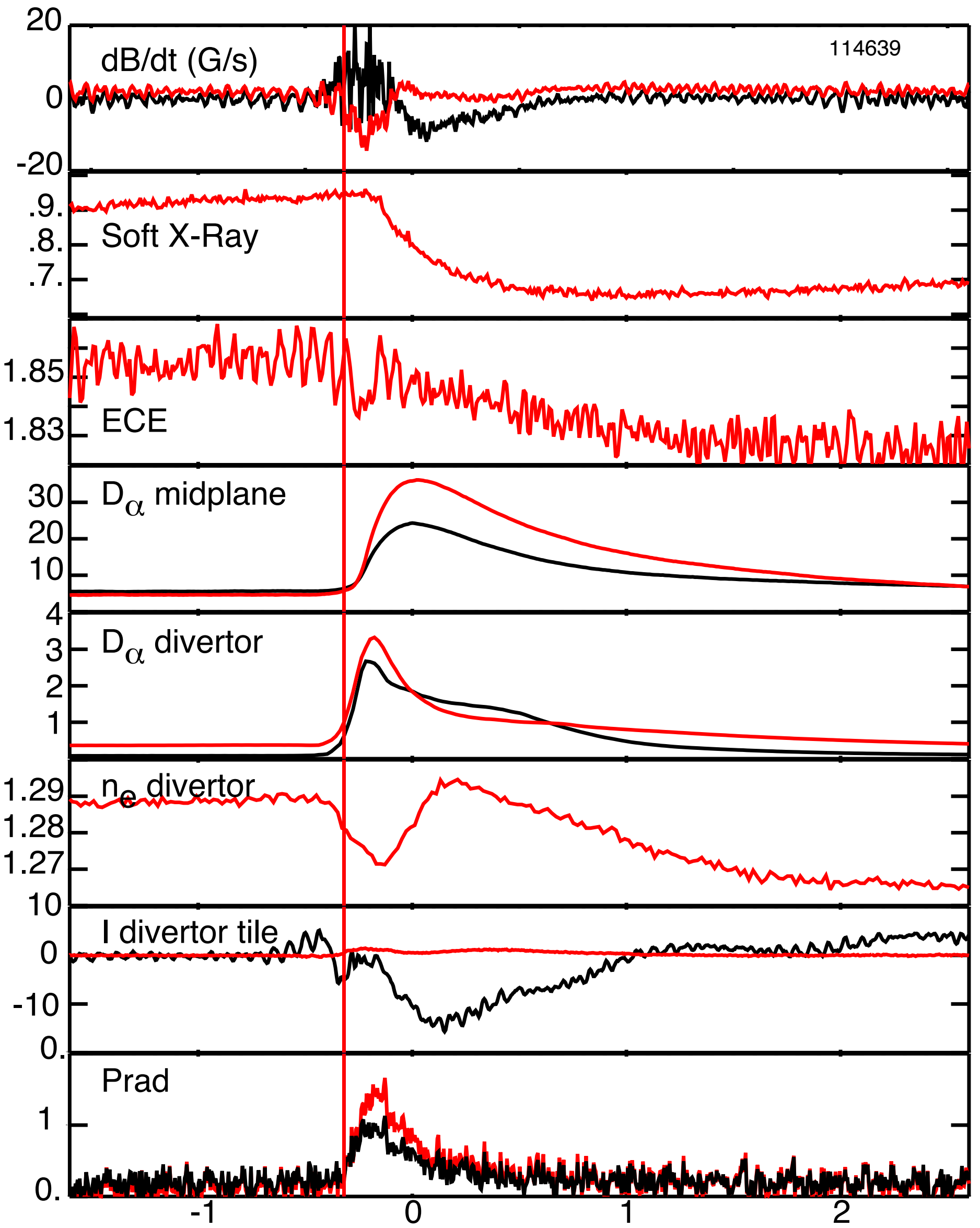

TIme (ms)

Fig. 2 


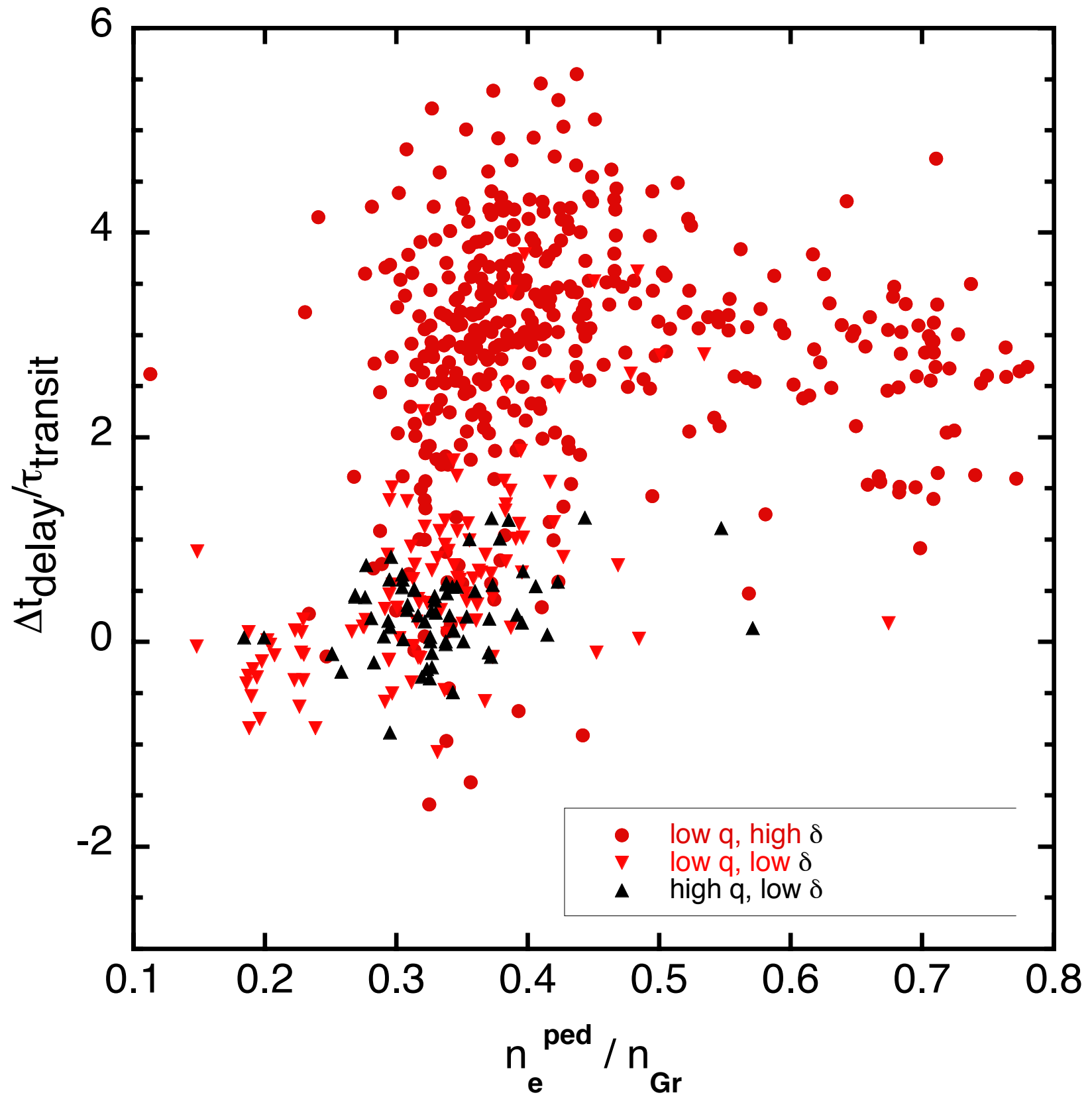

Fig. 3a 


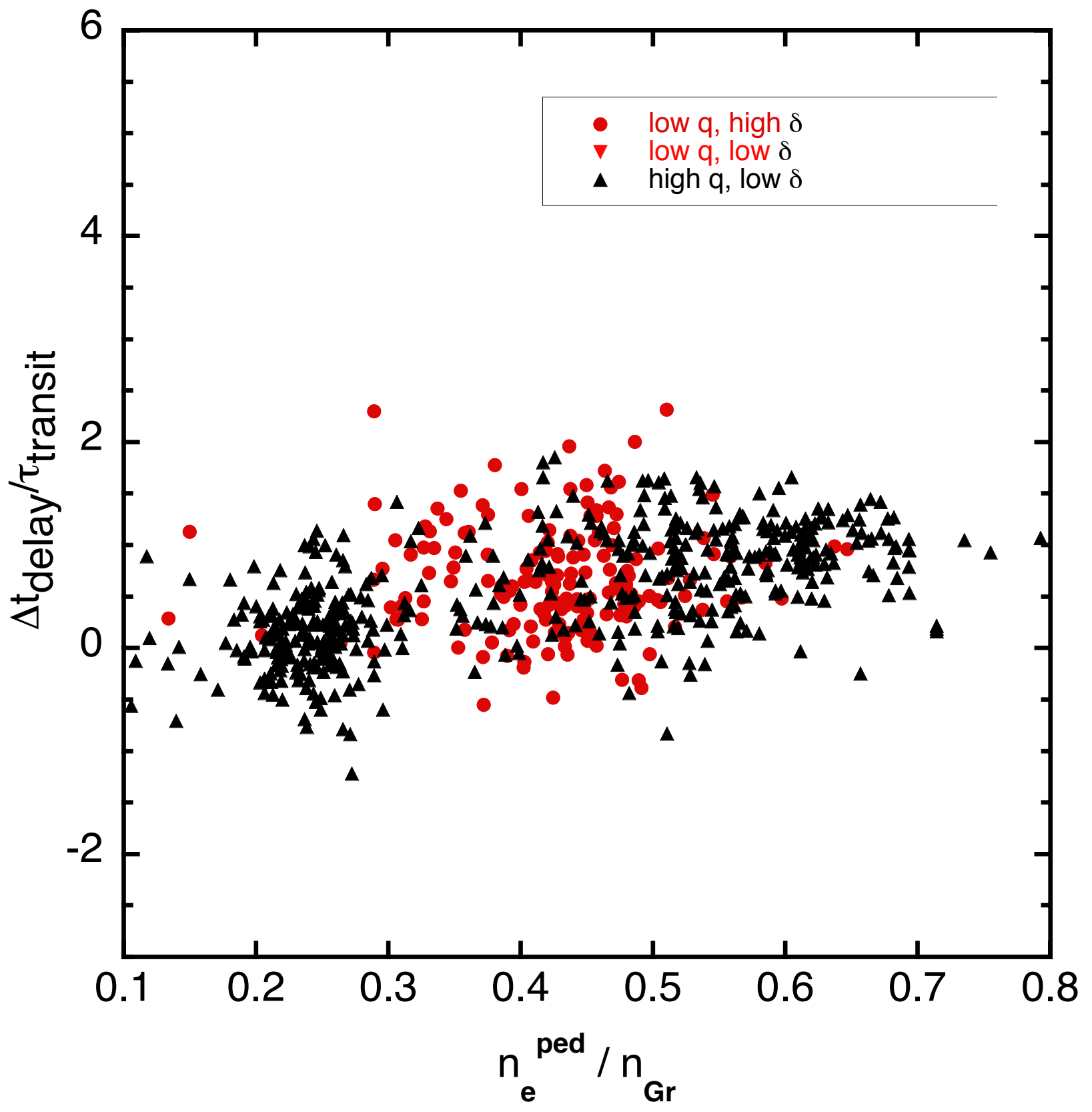

Fig. 3b 


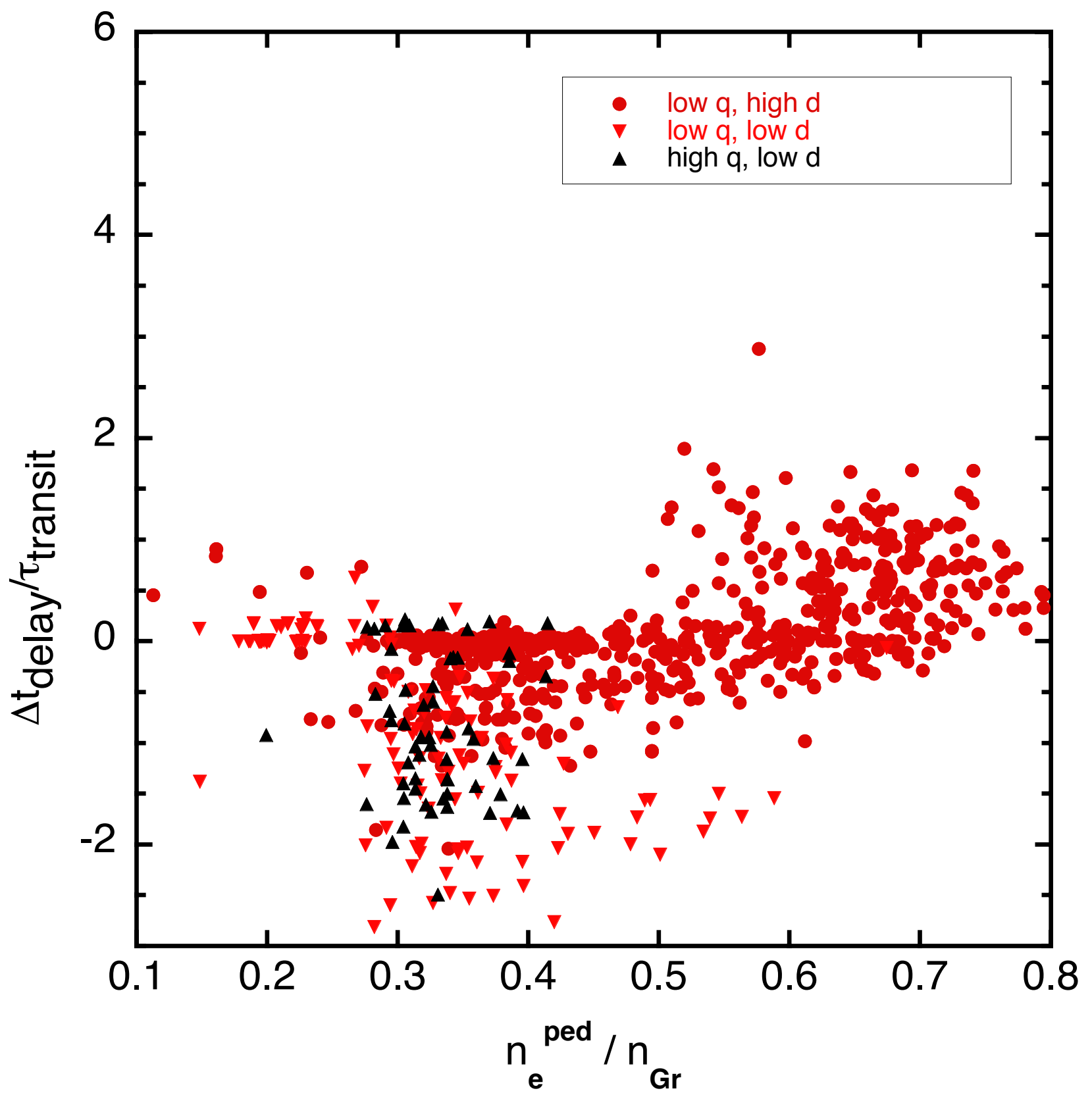

Fig.. 4a 


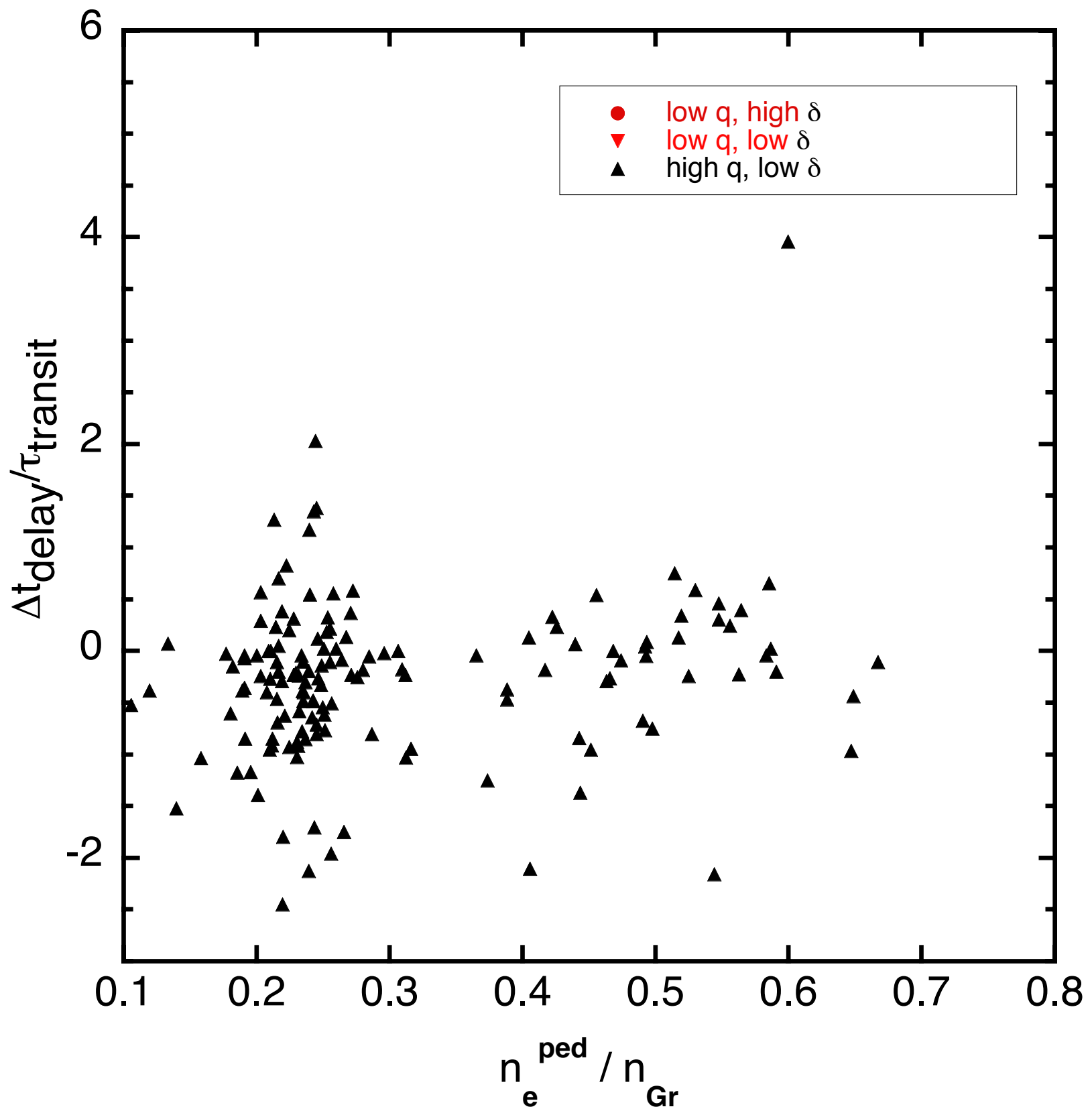

Fig. $4 b$ 


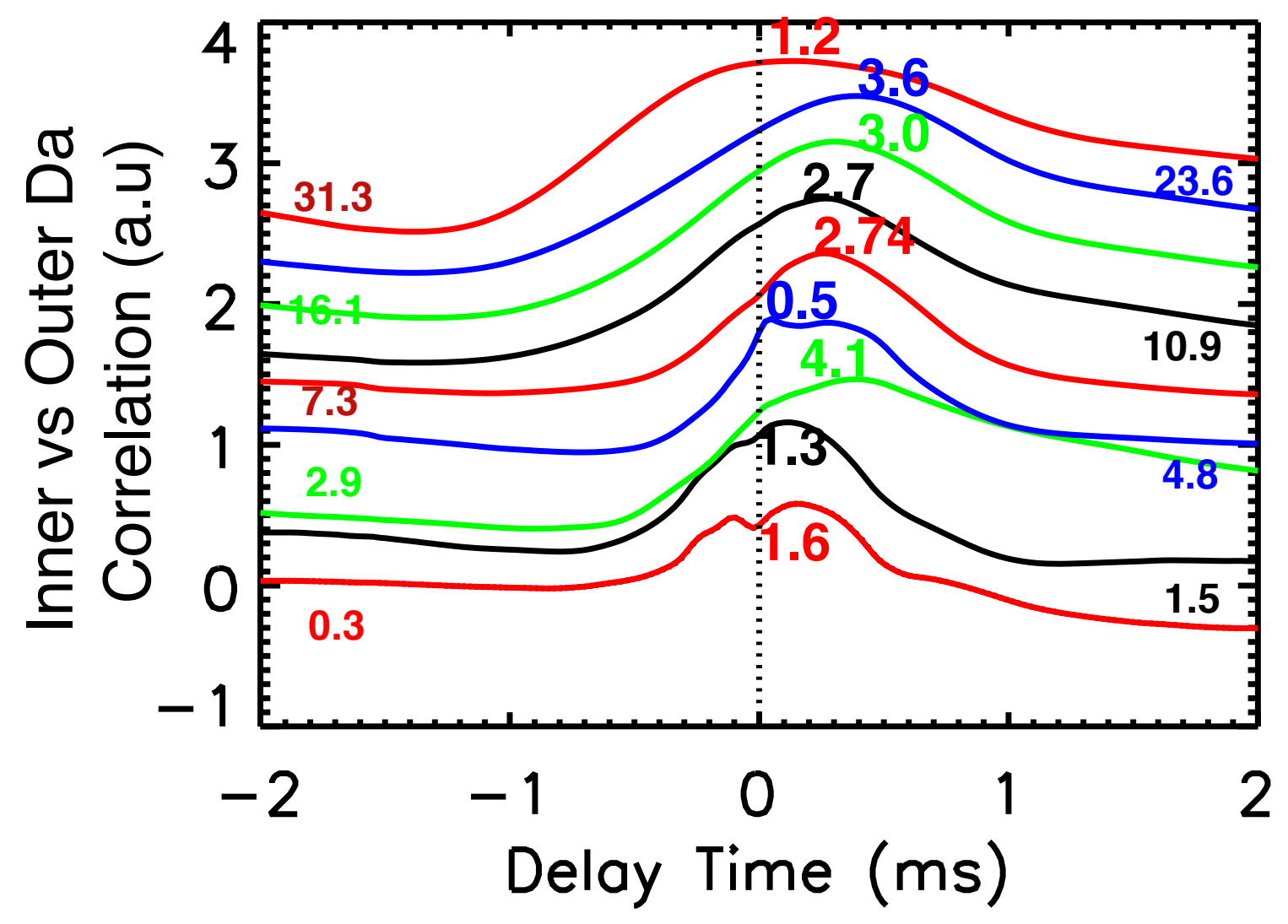




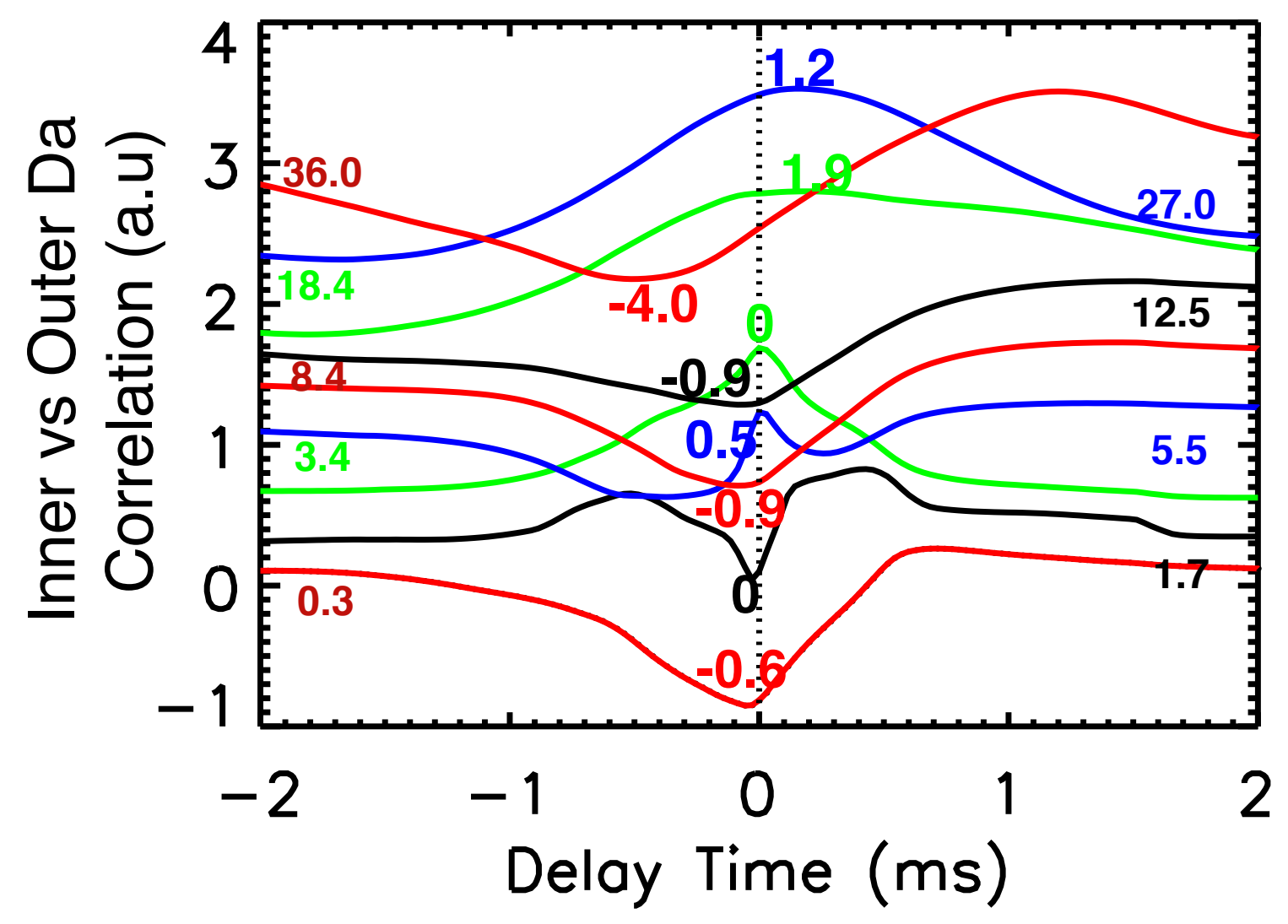




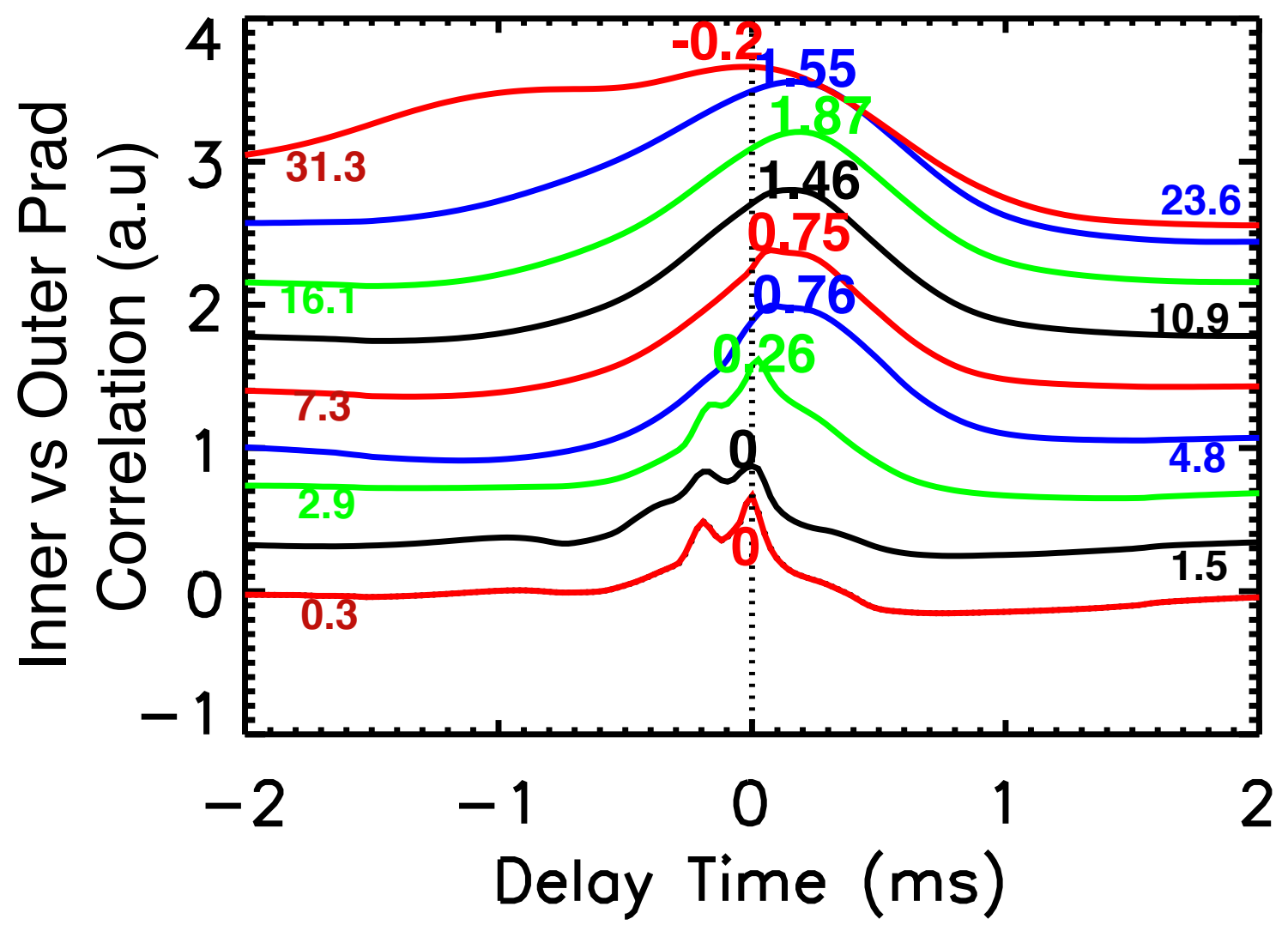




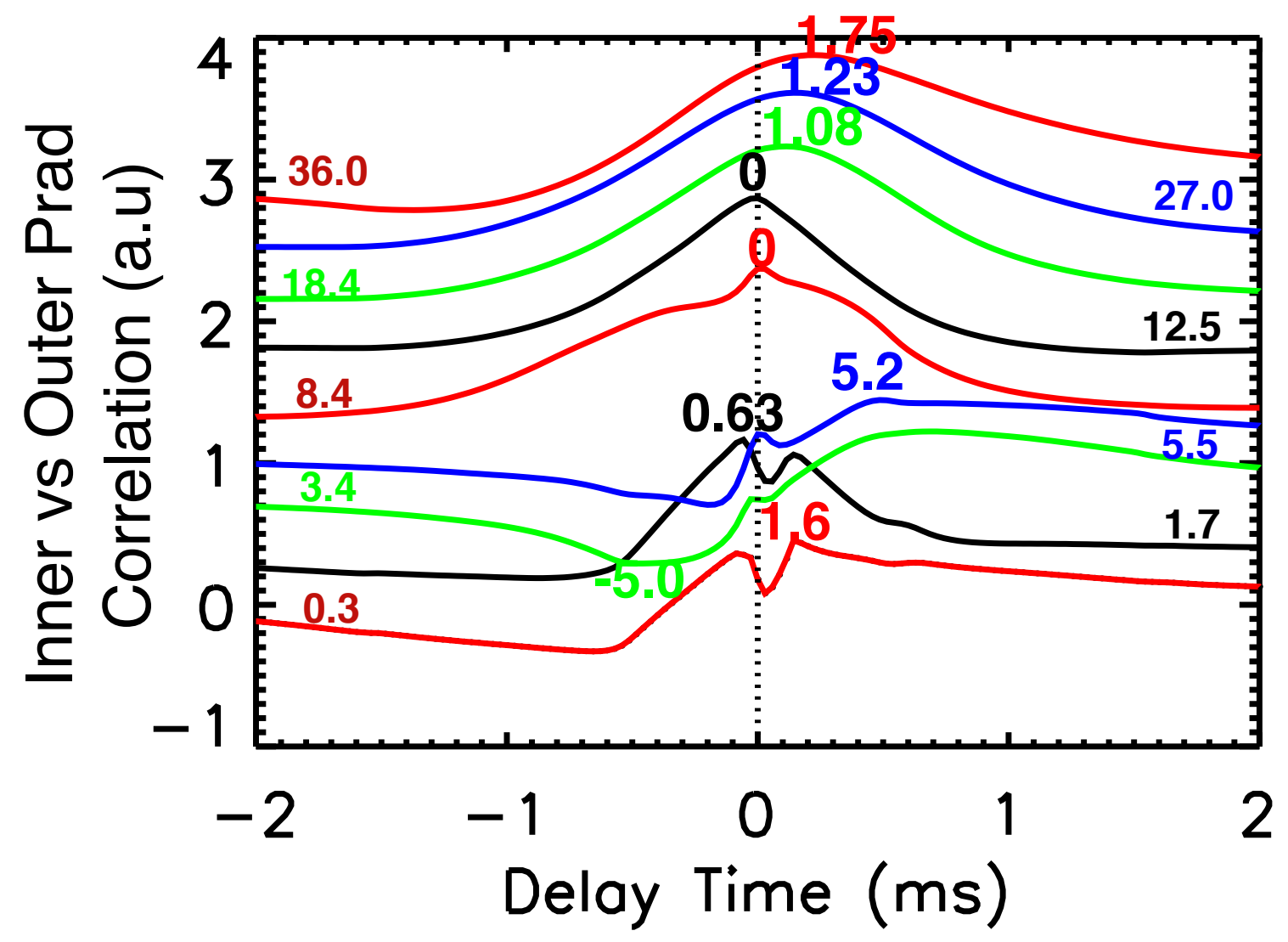


Univverilty of California

Lawrence Livermere National Laboratery

Technical Information Department

Livermore, CA 94551

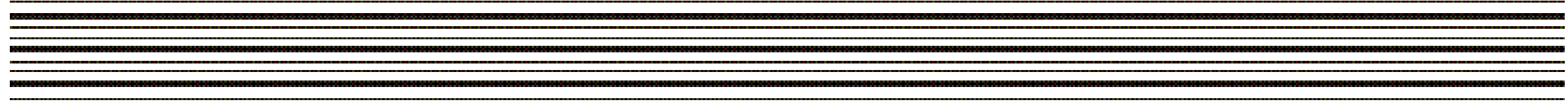

